\title{
Perbedaan Pengaruh Teknik Relaksasi Nafas Dalam Dan Kompres Hangat Dalam Menurunkan Dismenore Pada Remaja SMA Negeri 3 Padang
}

\author{
Vetty Priscilla ${ }^{a}$, Dwi Christina Rahayu Ningruma ${ }^{a}$,Lili Fajria ${ }^{a}$ \\ a Program Studi Ilmu Keperawatan Universitas Andalas \\ noe_nink_sweet@yahoo.com
}

\begin{abstract}
Some women experience dysmenorrhoea in each menstrual cycle, the intensity of pain that is felt even to severe and interfere with the activity. One non-pharmacological therapies that can be done to reduce dysmenorrhea relaxation techniques and breathing in the warm compresses. The purpose of this study to determine the influence of different relaxation techniques and breathing in the warm compresses in reducing dysmenorrhea in adolescent girls in SMA Negeri 3 Padang. This study uses a quasi experiment design. Sample as many as 32 teens divided in each treatment with the execution time of 20 minutes. Statistical tests used were t-test test and test of paired samples t-test free samples. The results showed there were significant reductions in the scale of dysmenorrhea in each group ( $p=$ 0.000). Bivariate analysis showed no significant difference scale reduction of dysmenorrhea in adolescents who were given relaxation techniques and breathing in the warm compresses. Based on this study suggested the teens use deep breathing relaxation techniques and warm compresses as one alternative to decrease pain of dysmenorrhea.
\end{abstract}

Keywords: Dysmenorrhea, deep breathing relaxation, warm compresses

\begin{abstract}
Abstrak: Sebagian wanita merasakan dismenore pada setiap siklus menstruasi, intensitas nyeri yang dirasakan bahkan sampai berat dan mengganggu aktivitas. Salah satu terapi non farmakologis yang bisa dilakukan untuk mengurangi dismenore teknik relaksasi nafas dalam dan kompres hangat. Tujuan dari penelitian ini untuk mengetahui perbedaan pengaruh teknik relaksasi nafas dalam dan kompres hangat dalam menurunkan dismenore pada remaja putri di SMA Negeri 3 Padang. Penelitian ini menggunakan desain Quasi Eksperiment. Sampel sebanyak 32 orang remaja yang dibagi dua pada masing-masing perlakuan dengan waktu pelaksanaan 20 menit. Uji statistik yang digunakan adalah uji t-tes sampel berpasangan dan uji t-test sampel bebas. Hasil menunjukkan terdapat penurunan yang bermakna pada skala dismenore pada masing-masing kelompok $(\mathrm{p}=0,000)$. Analisa bivariat menunjukkan tidak terdapat perbedaan bermakna penurunan skala dismenore pada remaja yang diberi teknik relaksasi nafas dalam dan kompres hangat. Berdasarkan penelitian ini disarankan kepada remaja menggunakan teknik relaksasi nafas dalam dan kompres hangat sebagai salah satu alternatif penurunan nyeri dismenore.
\end{abstract}

Kata kunci: Dismenore, relaksasi nafas dalam, kompres hangat

Menstruasi adalah keluarnya darah dari rahim melalui vagina dan keluar dari tubuh seorang wanita setiap bulan selama masa usia subur (Faizah,2000). Menstruasi adalah peristiwa keluarnya darah dari vagina karena meluruhnya lapisan dinding rahim yang banyak mengandung pembuluh darah (endometrium), pada saat sel telur tidak dibuahi. Sel telur ( yang hanya dimiliki oleh perempuan) hanya keluar sebulan sekali, dan apabila tidak ada pembuahan, misalnya melalui hubungan seksual, maka 14 hari kemudian sel telur itu akan gugur bersama dengan darah pada 
lapisan dinding rahim yang sebelumnya menebal. Hal ini biasanya akan berlangsung kurang lebih 28 hari (antara 21-35 hari). Siklus menstruasi dapat dipengaruhi oleh kondisi tertentu, seperti stress, pengobatan dan latihan olahraga. Pada masa remaja biasanya siklus menstruasi belum teratur, namun setelah dalam kurun waktu tertentu akan teratur. Menstruasi merupakan bagian dari proses reguler yang mempersiapkan tubuh wanita setiap bulannya untuk kehamilan (Keikos, 2007).

Setiap wanita memiliki pengalaman menstruasi yang berbeda-beda. Sebagian wanita mendapatkan menstruasi tanpa keluhan, namun tidak sedikit dari mereka yang mendapatkan menstruasi disertai keluhan berupa dismenore yang mengakibatkan rasa ketidaknyamanan serta berdampak terhadap gangguan aktivitas seperti : remaja tidak konsentrasi dalam menerima pelajaran, menurunnya prestasi belajar serta sering absen. Dismenore merupakan nyeri perut bagian bawah yang terkadang rasa nyeri tersebut meluas hingga ke pinggang, punggung bagian bawah dan paha (Baziad, 2003).

Insiden terjadinya dismenore merata $40-80 \%$ dan $5-10 \%$ wanita mengalami dismenore berat sampai dismenore yang tidak tertahankan. (Morgan dan Hamilton, 2009). Dismenore menyebabkan gangguan aktivitas sehari-hari dan harus absen dari sekolah 1-7 hari setiap bulannya pada $15 \%$ responden berusia 15 - 17 tahun. Dismenore tidak hanya menyebabkan gangguan aktivitas tetapi juga memberi dampak bagi fisik, psikologis, sosial dan ekonomi terhadap wanita diseluruh dunia misalnya: cepat letih, dan sering marah. Remaja dengan dismenore berat mendapat nilai yang rendah $(6.5 \%)$, menurunnya konsentrasi (87.1\%) dan absen dari sekolah $(80.6 \%)$ (Tangchai, 2004).

Penanggulangan nyeri haid yang umum dilakukan oleh remaja adalah mengkonsumsi obat-obatan penghilang rasa nyeri yang dijual bebas tanpa konsultasi ke tenaga kesehatan. Berdasarkan survei terhadap pelajar dari lima sekolah lanjutan pertama di Jakarta, pada 2002, didapatkan sedikit sekali di antara mereka yang berobat ke dokter. Padahal obat-obat penghilang nyeri hanya dapat mengurangi nyeri haid sementara waktu, dalam jangka panjang berdampak buruk ke ginjal dan liver (Baziad, 2004).

Secara umum penanganan nyeri dismenore terbagi dalam dua kategori yaitu pendekatan farmakologis dan non farmakologis. Secara farmakologis nyeri dapat ditangani dengan terapi analgesik yang merupakan metoda paling umum digunakan untuk menghilangkan nyeri. Walaupun analgesik dapat menghilangkan nyeri dengan efektif, namun penggunaan analgesik akan berdampak ketagihan dan akan memberikan efek samping obat yang berbahaya bagi pasien. Secara non farmakologik antara lain kompres hangat, teknik relaksasi seperti nafas dalam dan yoga (Potter \& Perry, 2005). Dalam hal ini perawat berperan dalam penanganan secara non-farmakologis.

Relaksasi merupakan teknik pengendoran atau pelepasan ketegangan, misalnya: bernafas dalam dan pelan. Selain dapat menurunkan intensitas nyeri, teknik relaksasi nafas dalam juga dapat meningkatkan ventilasi paru dan meningkatkan oksigen darah (Smeltzer \& Bare, 2002). Prinsip yang mendasari penurunan nyeri oleh teknik relaksasi nafas dalam terletak pada fisiologi sistem saraf otonom yang merupakan bagian dari sistem saraf perifer yang mempertahankan homeostatis lingkungan internal individu. Penggunaan kompres hangat diharapkan dapat meningkatkan relaksasi otot-otot dan mengurangi nyeri akibat spasme atau kekakuan serta memberikan rasa hangat lokal. Pada umumnya panas cukup berguna untuk pengobatan. Panas meredakan iskemia dengan menurunkan kontraksi dan meningkatkan sirkulasi. Kompres hangat dapat menyebabkan pelepasan endorfin tubuh sehingga memblok transmisi stimulasi nyeri. Menurut teori gate-control kompres hangat dapat mengaktifkan (merangsang) serat-serat non- 
nosiseptif yang berdiameter besar ( A- $\alpha$ dan A- $\beta$ ) untuk 'menutup gerbang' bagi seratserat yang berdiameter kecil ( A- $\delta$ dan $C$ ) yang berperan dalam menghantarkan nyeri, sehingga nyeri dapat dikurangi (Price \& Wilson, 2006). Upaya menutup pertahanan tersebut merupakan dasar terapi menghilangkan nyeri.

Hasil survey pendahuluan yang dilakukan peneliti pada tanggal 18 Januari 2012 terhadap 181 orang siswi di kelas XI SMA Negeri 3 Padang didapatkan jumlah siswi yang mengalami nyeri menstruasi sebanyak 155 orang siswi dengan 123 orang mengalami nyeri ringan, 16 orang nyeri sedang, dan 16 orang mengalami nyeri berat hanya 5 orang yang pernah menggunakan teknik relaksasi nafas dalam dan kompres hangat sebagai salah satu cara penanggulangan nyeri haid secara non farmakologi. Pemilihan di SMA N 3 Padang dikarenakan program PIK-KRR tidak berjalan disana, dimana sekolah ini termasuk sekolah yang unggul. Berdasarkan wawancara penulis dengan guru piket serta wali kelas di SMA Negeri 3 Padang didapatkan keterangan bahwa sebanyak 20 orang siswi-siswi dalam 1 bulan yang mengalami dismenore biasanya sering minta izin pulang sebelum jam pulang sekolah dengan alasan mereka tidak sanggup mengikuti kegiatan belajar mengajar. Upaya penanganan dismenorea yang dilakukan oleh sebagian siswi adalah mengoleskan minyak kayu putih pada daerah nyeri, tiduran, dan minum obat pengurang rasa sakit.

\section{METODE}

Penelitian ini menggunakan desain Quasi Eksperiment dengan menggunakan kelompok eksperimen yang diberikan perlakuan tanpa kelompok kontrol dengan pendekatan non equivalent control group. Pada kelompok subjek (treatment) dilakukan pengukuran skala nyeri dismenore sebelum menjalani teknik relaksasi nafas dalam dan kompres hangat ( pre test). Pengukuran yang sama kembali dilakukan pada kelompok subjek (treatment) tersebut setelah diberikan perlakuan berupa teknik relaksasi nafas dalam dan kompres hangat untuk mengetahui perubahan skala nyeri dismenore siswi.

Yang menjadi populasi dalam penelitian ini adalah seluruh siswi SMA 3 Padang yang mengalami nyeri dismenore. Jumlah sampel yang digunakan pada penelitian ini yaitu 32 orang sampel yang mengalami dismenore sedang sebanyak 16 orang dan dismenore berat sebanyak 16 orang

Data yang dikumpulkan pada penelitian ini berupa data primer karena pengumpulan data dilakukan secara langsung terhadap responden dengan menggunakan lembar pengukuran skala nyeri Mankoski Pain Scale, wawancara, lembar observasi. Secara umum lembar observasi berisi tentang biodata responden, tanggal menstruasi serta hasil pengukuan skala dismenore sebelum dan sesudah melakukan teknik relaksasi nafas dalam dan kompres hangat.

Analisa ini menggambarkan distribusi dari masing-masing variabel yang diteliti yaitu skala dismenore sebelum dan sesudah melakukan teknik relaksasi nafas dalam dan kompres hangat. Sedangkan Analisa bivariat digunakan untuk mengetahui perubahan skala dismenore sebelum dan sesudah pemberian teknik relaksasi nafas dalam dan perubahan skala dismenore sebelum dan sesudah pemberian kompres hangat. Uji Shapiro-Wilk untuk menentukan jenis Uji hipotesis yang digunakan, jika interprestasi kemaknaan adalah bermakna bila $(\mathrm{p})>0,05$ maka data berdistribusi normal dan Uji hipotesis yang digunakan adalah Uji parametric yaitu Uji $\mathrm{T}$ test, tetapi bila interprestasi kemaknaan $(\mathrm{p})<0,05$ maka data berdistribusi tidak normal dan Uji hipotesis yang digunakan adalah Uji non parametric yaitu Uji Wilcoxson.

\section{HASIL DAN PEMBAHASAN}

Dari hasil pengambilan data pada remaja putri di SMA Negeri 3 Padang 
selama 4 minggu mulai dari tanggal 26 Maret sampai 10 Juli 2012 dengan jumlah responden pada saat pengambilan data awal sebanyak 32 orang siswi yang mengalami nyeri sedang dan berat. Responden diberikan perlakuan (teknik relaksasi nafas dalam) pada 16 orang yang terdiri dari 8 orang mengalami nyeri sedang dan 8 orang mengalami nyeri berat sebanyak 3 kali selama 20 menit, dan diberikan kompres hangat pada 16 orang yang terdiri dari 8 orang mengalami nyeri sedang dan 8 orang lainnya mengalami nyeri berat selama 20 menit.

Gambaran skala dismenore sebelum dilakukan teknik relaksasi nafas dalam nilai minimum 3 , nilai maksimum 9 , dengan ratarata 6,19 dan standar deviasi 1,682 dan sesudah dilakukannya teknik relaksasi nafas dalam nilai minimum 1 , nilai maksimum 6 , dengan rata-rata 3,56 dan standar deviasi 1,825 . Rata-rata terjadi penurunan skala dismenore setelah melakukan teknik relaksasi nafas dalam.

Hasil uji statistik dengan menggunakan Uji Beda Dua mean Berpasangan (Paired Sampel) didapatkan rata-rata skala dismenore pretest kelompok teknik relaksasi nafas dalam adalah 6,19 dengan skala dismenore minimum 3 dan maksimum 9 dan rata-rata skala dismenore postest adalah 3,56, dengan skala dismenore minimum 1 dan maksimum 6 . Hasil uji statistik didapatkan nilai $\mathrm{p}=0,000(\mathrm{p}<0,05)$, maka dapat disimpulkan terdapat perbedaan penurunan bermakna skala dismenore pretest - postest pada kelompok teknik relaksasi nafas dalam

Secara umum penanganan nyeri dismenore terbagi dalam dua kategori yaitu pendekatan farmakologis dan non farmakologis. Secara farmakologis nyeri dapat ditangani dengan terapi analgesik yang merupakan metoda paling umum digunakan untuk menghilangkan nyeri. Walaupun analgesik dapat menghilangkan nyeri dengan efektif, namun penggunaan analgesik akan berdampak ketagihan dan akan memberikan efek samping obat yang berbahaya bagi pasien. Secara non farmakologik antara lain kompres hangat, teknik relaksasi seperti nafas dalam dan yoga (Potter \& Perry, 2005). Dalam hal ini perawat berperan dalam penanganan secara non-farmakologis.

Nyeri adalah alasan utama seseorang untuk mencari bantuan perawatan (Smeltzer \& Bare, 2002). Nyeri bersifat subjektif, tidak ada dua individu yang mengalami nyeri yang sama dan tidak ada dua kejadian nyeri yang sama menghasilkan respon atau perasaan yang identik pada seorang individu (Potter \& Perry, 2006). Nyeri haid (dismenore) merupakan nyeri yang diakibatkan karena terjadi kontraksi otot rahim akibat peningkatan prostaglandin sehingga menyebabkan vasospasme dari arteriol uterin yang menyebabkan terjadinya iskemia dan kram pada abdomen bagian bawah yang akan merangsang rasa nyeri di saat datang bulan (Robert dan David, 2004). Dismenore yang sedemikian hebatnya memaksa penderita untuk istirahat dan meninggalkan pekerjaan atau cara hidupnya sehari-hari, untuk beberapa jam atau beberapa hari (Simanjuntak, 2008).

Prinsip yang mendasari penurunan nyeri oleh teknik relaksasi terletak pada fisiologi system syaraf otonom yang merupakan bagian dari system syaraf perifer yang mempertahankan homeostatis lingkungan internal individu. Pada saat terjadi pelepasan mediator kimia seperti bradikinin, prostaglandin dan substansi $\mathrm{p}$, akan merangsang syaraf simpatis sehingga menyebabkan vasokostriksi yang akhirnya meningkatkan tonus otot yang menimbulkan berbagai efek seperti spasme otot yang akhirnya menekan pembuluh darah, mengurangi aliran darah dan meningkatkan kecepatan metabolisme otot yang menimbulkan pengiriman implus nyeri dari medulla spinalis ke otak dan dipresepsikan sebagai nyeri (Smeltzer \& Bare, 2002)

Priharjo (2003), menjelaskan bahwa paling tidak ada tiga hal penting yang menjadikan tindakan relaksasi bermakna secara signifikan terhadap skala nyeri yaitu posisi yang tepat, pikiran yang tenang dan lingkungan yang tenang. Kondisi tersebut 
juga terjadi pada responden jika teknik relaksasi nafas dalam dilakukan secara baik ditambah dengan pikiran yang tenang dan kondisi lingkungan yang tenang, sangat memberikan kontribusi dalam proses penurunan skala nyeri dismenore pada remaja.

Dari 16 orang responden sebelum diberikan teknik relaksasi nafas dalam 8 orang diantaranya mengalami skala dismenore berat, dan 8 orang mengalami skala dismenore ringan. Setelah diberikan intervensi teknik relaksasi nafas dalam terjadi penurunan skala dismenore dimana 8 orang yang mengalami skala dismenore berat mengalami penurunan menjadi skala sedang, sedangkan 8 orang yang mengalami skala dismenore sedang mengalami penurunan menjadi skala dismenore ringan.

Hal ini sesuai dengan penelitian Ernawati (2010), dimana frekuensi responden yang mengalami nyeri menstruasi sedang menurun dari 31 orang sebelum diberikan teknik relaksasi nafas dalam menjadi 11 orang setelah diberikan teknik relaksasi nafas dalam. Yang berarti bahwa teknik relaksasi nafas dalam yang diberikan dapat menurunkan tingkat nyeri dari nyeri sedang menjadi nyeri ringan.

Teknik relaksasi nafas dalam yang dilakukan secara berulang akan menimbulkan rasa nyaman. Adanya rasa nyaman inilah yang akhirnya akan meningkatkan toleransi seseorang terhadap nyeri. Orang yang memiliki toleransi nyeri yang baik akan mampu beradaptasi terhadap nyeri dan akan memilki mekanisme koping yang baik pula. Selain meningkatkan toleransi nyeri, rasa nyaman yang dirasakan setelah melakukan nafas dalam juga dapat meningkatkan ambang nyeri sehingga dengan meningkatkan ambang nyeri maka nyeri yang terjadi berada pada skala 2 (sedang) menjadi skala 1 (nyeri ringan) setelah dilakukan teknik relaksasi nafas dalam (Kozier, 2004). Hal ini sesuai dengan pengamatan peneliti bahwa responden yang melakukan teknik relaksasi nafas dalam dengan baik dan didukung dengan lingkungan yang tenang akan memberikan efek penurunan intensitas nyeri secara nyata.

Wall (1965), menjelaskan bahwa implus nyeri dihantarkan saat sebuah pertahanan dibuka dan implus dihambat saat sebuah pertahanan tertutup. Upaya menutup pertahanan tersebut merupakan dasar terapi untuk menghilangkan nyeri. Pemblokan ini dapat dilakukan melalui mengalikan perhatian ataupun dengan tindakan relaksasi. Teknik relaksasi napas dalam dapat menurunkan intensitas nyeri dengan cara merelaksasikan otot-otot skelet yang mengalami spasme yang disebabkan oleh peningkatan prostaglandin sehingga terjadi vasodilatasi pembuluh darah dan akan meningkatkan aliran darah ke daerah yang mengalami spasme dan iskemic.

Teori lain yang mendukung bahwa teknik relaksasi nafas dalam dapat menurunkan intensitas nyeri adalah teori huges dkk (2001). Menurutnya dalam keadaan tertentu tubuh mampu mengeluarkan opoid endogen yaitu endorphin dan enkefalin. Zat -zat tersebut memiliki sifat mirip morfin dengan efek analgetik yang membentuk suatu "system penekan nyeri". Tehnik relaksasi nafas dalam merupakan salah satu keadan yang mampu merangsang tubuh untuk mengeluarkan opoid endogen sehingga terbentuk system penekan nyeri yang akhirnya akan menyebabkan penurunan intensitas nyeri. Hal inilah yang menyebabkan adanya perbedaan penurunan intensitas nyeri sebelum dan sesudah dilakukan teknik relaksasi nafas dalam, dimana setelah dilakukan teknik relaksasi nafas dalam terjadi penurunan intensitas nyeri.

Gambaran skala dismenore sebelum dilakukan kompres hangat nilai minimum 3, nilai maksimum 8 , dengan rata-rata 6,31 dan standar deviasi 1,662 dan sesudah dilakukannya kompres hangat nilai minimum 1, nilai maksimum 6 dengan ratarata 3,81 dan standar deviasi 1,601. Ratarata terjadi penurunan skala dismenore setelah melakukan kompres hangat. 
Hasil uji statistik dengan Berpasangan (Paired Sampel) didapatkan rata-rata skala dismenore pretest kelompok kompres hangat adalah 6,31 dengan skala dismenore minimum 3 dan maksimum 9. Sedangkan rata-rata skala dismenore postest 3,81 dengan skala dismenore minimum 1 dan maksimum 6. Hasil uji statistik didapatkan nilai $\mathrm{p}=0,000(\mathrm{p}<0,05)$, maka dapat disimpulkan terdapat perbedaan penurunan bermakna skala dismenore pretest - postest pada kelompok kompres hangat.

Dari 16 orang responden yang diberikan kompres hangat 9 orang responden mengalami nyeri berat, dan selebihnya mengalami nyeri sedang. Setelah diberikan kompres hangat terjadi penurunan skala nyeri dimana 9 orang yang mengalami skala dismenore berat menurun menjadi skala sedang, dan 7 orang yang mengalami skala dismenore sedang mengalami penurunan menjadi skala ringan.

Hal penelitian ini sesuai dengan penelitian yang dilakukan Arofiati \& Kurniasih (2004), dimana frekuensi responden yang mengalami nyeri menstruasi sedang menurun dari 10 orang sebelum diberikan kompres hangat menjadi 5 orang setelah diberikan kompres hangat. Yang berarti bahwa kompres hangat yang diberikan dapat menurunkan tingkat nyeri dari nyeri sedang menjadi nyeri ringan. Hal ini diperkuat oleh penelitian yang dilakukan oleh Smith (nd, cit/ dikutip dalam Kirn, 2000) yang membandingkan penggunaan kompres hangat dalam menurunkan intensitas nyeri dengan penggunaan ibuprofen. Sebanyak 81 orang wanita terlibat dalam penelitian ini yang diberikan perlakuan selama 2 hari yang dibagi dalam 4 kelompok yaitu kelompok yang tidak diberikan apa-apa, kelompok yang diberikan kompres hangat selama 12 jam secara berurutan, kelompok yang diberikan ibuprofen $400 \mathrm{mg}$ setiap 6 jam, dan kelompok yang diberikan kompres hangat serta ibuprofen. Didapatkan bahwa ternyata kompres hangat yang diberikan sama baiknya dalam menurunkan nyeri menstruasi bila dibandingkan dengan penggunaan ibuprofen. Bahkan dikatakan juga oleh Akin, 2004 bahwa penggunaan kompres hangat untuk mengatasi nyeri menstruasi primer lebih baik bila dibandingkan dengan penggunaan acetaminofen secara oral.

Penurunan intensitas nyeri ini sesuai dengan teori dalam Potter dan Perry (2006), yang menyatakan bahwa kompres hangat merupakan salah satu bentuk terapi nonfarmakologi yang dapat digunakan untuk mengurangi nyeri. Hal ini juga sesuai dengan teori "gate control" yang dikemukakan oleh Melzack dan Wall, bahwa impuls nyeri yang berjalan ke korteks serebri dapat dimodifikasi, diatur bahkan dihambat sehingga sensasi nyeri dapat dikurangi. Salah satu mekanisme yang dapat dilakukan adalah pemberian kompres hangat. Kompres hangat yang diberikan dapat merangsang (mengaktifkan) seratserat saraf non-nosiseptif berdiameter besar yang tidak menghantarkan nyeri yaitu serat A- $\alpha$ dan serat A- $\beta$. Aktivitas pada serat saraf ini cenderung menghambat transmisi nyeri atau menutup gerbang bagi serat saraf nyeri yang mentransmisikan nyeri ke otak yaitu serat saraf nyeri yang mentransmisikan nyeri ke otak yaitu serat saraf $A-\delta$ dan serat $\mathrm{C}$, dengan cara merangsang neuron-neuron substansia gelatinosa inhibitorik di kornu dorsalis medula spinalis sehingga input ke sel $\mathrm{T}$ berkurang. Dengan berkurangnya input ke sel $\mathrm{T}$ di medula spinalis, maka impuls nyeri yang akan disampaikan ke otak berkurang sehingga nyeri yang akan dirasakan juga akan berkurang. Selain itu pemberian kompres hangat juga dapat memperlancar sirkulasi karena efek panas yang diberikan serta dapat menurunkan spasme dan kontraksi otot perut yang berlebihan selama menstruasi sehingga nyeri menstruasi yang dirasakan dapat berkurang.

Sementara hipotesis lain mengatakan bahwa kompres hangat dapat merangsang tubuh untuk mengeluarkan endorfin dan neurotransmiter lain (opiat endogen) yang 
dapat menghambat nyeri. Opoid endogen merupakan zat yang dihasilkan oleh tubuh yang bersifat mirip dengan morfin dan berikatan dengan reseptor opoid yang akan efek analgesik dan euforia. Saat ini morfin merupakan suatu zat yang paling luas digunakan untuk mengobati nyeri berat karena merupakan analgesik paling kuat.

Endorfin bekerja dengan mengikat reseptor opoid yang ada di sistem limbik, otak tengah, medula spinalis dan usus. Reseptor opoid dan opoid endogen ini kemudian membentuk suatu 'sistem penekan nyeri' ' intrinsik. Ikatan antara opiat dengan reseptor ini yang akan dapat mengurangi nyeri dengan mencegah dibebaskannya berbagai neurotransmitter penghasil nyeri (Price \& Wilson, 2006).

Penelitian ini juga membenarkan teori lain yang menyatakan bahwa kompres hangat akan dapat menurunkan pengiriman signal ke otak (Gosana, 2001). Hal ini terbukti dengan adanya penurunan intensitas nyeri yang dirasakan setelah diberikan kompres hangat.

Tabel 1. Perbedaan Pengaruh Teknik Relaksasi Nafas Dalam dan Kompres Hangat Dalam Menurunkan Dismenore Pada Remaja SMA N 3 Padang Tahun 2012

\begin{tabular}{ccccc}
\hline Teknik Non Farmakologis & Mean & $\begin{array}{c}\text { Std. } \\
\text { deviation }\end{array}$ & Std.Error Mean & P \\
\hline Teknik Relaksasi Nafas Dalam & 2,63 & 0,957 & 0,239 & \multirow{2}{*}{0,705} \\
Kompres Hangat & 2,50 & 0,894 & 0,224 & \\
\hline
\end{tabular}

Dari Tabel 1, didapatkan hasil penelitian dengan uji independent sample $t$ test rata-rata selisih skala dismenore pada kelompok teknik relaksasi nafas dalam adalah 2,63 dengan standar deviasi 0,957 dan rata-rata selisih skala dismenore pada kelompok kompres hangat adalah 2,50 dengan standar deviasi 0,894. Hasil uji statistik dengan menggunakan uji independent sample $t$ test perbedaan nilai rata-rata skala dismenore pada kelompok teknik relaksasi nafas dalam dan kompres hangat didapatkan nilai $p=0,705(p>0,005)$, maka dapat disimpulkan tidak terdapat perbedaan bermakna penurunan skala dismenore pada remaja yang diberi teknik relaksasi nafas dalam dan kompres hangat.

Hasil uji statistik dengan menggunakan Uji Beda Dua mean tidak Berpasangan (Independent sample $t$ Test) didapatkan rata-rata selisih skala dismenore kelompok teknik relaksasi nafas dalam adalah 2,63 dengan standar deviasi 0,957 dan rata-rata selisih skala dismenore kelompok kompres hangat adalah 2,50 dengan standar deviasi 0,894. Hasil uji statistik didapatkan nilai $\mathrm{p}=0,705(\mathrm{p}<0,05)$, maka dapat disimpulkan tidak terdapat perbedaan bermakna penurunan skala dismenore pada remaja yang diberi teknik relaksasi nafas dalam dan kompres hangat.

Jika dilihat dari rata-rata selisih penurunan skala dismenore kelompok teknik relaksasi nafas dalam pretest adalah 6,19 , sedangkan untuk rata-rata selisih penurunan skala dismenore postest adalah 3,56 maka dapat disimpulkan untuk rata-rata selisih skala dismenore pretest dan posttest kelompok teknik relaksasi nafas dalam adalah 2,63. Sedangkan untuk rata-rata selisih skala dismenore pretest kelompok kompres hangat adalah 6,31 sedangkan untuk rata-rata selisih penurunan skala dismenore postest adalah 3,81 maka dapat disimpulkan untuk rata-rata selisih skala dismenore pretest dan posttest kelompok kompres hangat dalam adalah 2,50. Maka dapat disimpulkan tidak ada perbedaan yang signifikan antara kedua metoda dan kedua teknik ini sama-sama efektif dalam menurunkan skala dismenore. 
Dalam keadaan rileks maka otot tidak menjadi tegang dan tidak memerlukan sedemikian banyak oksigen dan gula, jantung berdenyut lebih lambat, tekanan darah menurun, nafas lebih mudah, hati akan mengurangi pelepasan gula, natrium dan kalium dalam tubuh kembali seimbang, dan keringat akan berhenti bercucuran. Dalam keadaan rileks, tubuh juga menghentikan produksi hormone adrenalin dan semua hormon yang diperlukan saat stress. Oleh karena hormon seks estrogen dan progesterone serta hormon stress adrenalin diproduksi dari blok kimiawi yang sama, ketika mengurangi stress, berarti juga telah mengurangi produksi kedua hormone tersebut. Pentingnya relaksasi nafas dalam untuk memberikan kesempatan bagi tubuh memproduksi hormon yang penting untuk mendapatkan haid tanpa rasa nyeri. (Dito Anurogo, 2011)

Suhu panas dapat mengurangi ketengangan otot. Setelah otot rileks, rasa nyeri akan berangsur hilang. Kompres hangat merupakan salah satu cara terbaik mengatasi nyeri. Karena secara teoritis ujung-ujung saraf nyeri akan mengirimkan signal nyeri lebih sedikit ke dalam otak (saraf pusat) pada waktu dihangatkan. Aplikasi panas (kompres hangat) merupakan tindakan sederhana yang telah lama diketahui. Panas dapat melebarkan pembuluh darah dan meningkatkan aliran darah lokal. Karena meningkatkan aliran darah, panas mungkin meredakan nyeri dengan menyingkirkan produk-produk inflamasi, seperti bradikidin, histamin, dan prostaglandin yang menimbulkan nyeri lokal. Panas juga mungkin merangsang serat saraf yang menutup gerbang sehingga transmisi impuls nyeri ke medulla spinalis dan otak dapat dihambat. ( Price \& Wilson, 2006)

Oleh karena itu teknik relaksasi nafas dalam dan kompres hangat dapat digunakan dalam mengurangi nyeri dismenore karena kedua teknik ini dapat mengurangi ketegangan otot yang dirasakan selama menstruasi. Selain itu kedua teknik ini dapat dilakukan dirumah.

\section{KESIMPULAN DAN SARAN}

Berdasarkan hasil penelitian yang dilakukan di SMA N 3 Padang tahun 2012 dapat diambil kesimpulan sebagai berikut, terjadi penurunan skala dismenore pada remaja SMA N 3 Padang pada kelompok yang mendapatkan teknik relaksasi nafas dalam. Sedangkan pada kelompok yang kompres hangat terjadi penurunan skala dismenore pada remaja SMA N 3 Padang pada kelompok yang mendapatkan kompres hangat. Tidak terdapat perbedaan yang bermakna penurunan skala dismenore pada remaja SMA N 3 Padang akibat teknik relaksasi nafas dalam dan kompres hangat. Peneliti menyarankan pada responden (remaja) agar dapat memanfaatkan teknik relaksasi nafas dalam ataupun kompres hangat untuk mengurangi nyeri menstruasi sebagai alternatif cara non farmakologi yang aman dan mudah untuk dilakukan dirumah, bagi institusi pendidikan, agar dapat memberikan informasi kepada siswi tentang pemanfaatan teknik relakasasi nafas dalam ataupun kompres hangat sebagai salah satu alternatif secara non farmakologi dalam menurunkan nyeri menstruasi, sehingga dapat mengurangi pemakaian obat analgesik bagi siswi yang mengalami dismenore primer. Pada peneliti selanjutnya, untuk dapat melakukan penelitian tentang pengaruh teknik relaksasi nafas dalam ataupun kompres hangat dalam segi waktu pelaksanaannya untuk mengurangi nyeri responden terutama pada responden yang mengalami nyeri berat setiap bulannya.

\section{DAFTAR PUSTAKA}

Akin. (2004). Continous, low-level, topical heat wrap therapy as compared to cetaminofen for primary dysmenorrhea. www.ncbi.nlm.nih.gov/entrez/query.fcgi $? \mathrm{db}=$ PubMed \&cmd=Retrieve \&list ids $=11239634 \& d o p t=$ Abstract. Diakses tanggal 27 April 2012

Anurogo, D. (2011). Cara Jitu Mengatasi Nyeri Haid. Yogyakarta : C.V Andi Offset 
Arofiati F., Kurniasih, A. (2004). Pengaruh pemberian kompres hangat kering terhadap tingkat nyeri pada saat menstruasi di panti asuhan putri ' Aisyiyah Yogyakarta 2004. Jurnal Mutiara Medika (Jurnal Kedokteran dan Kesehatan). 1(4):30-47

Badziad, A. (2003). Endokrinologi dan ginekologi (edisi 2). Jakarta: Media Aesculapius Fakultas Kedokteran Universitas.

Ernawati. (2010). Terapi Relaksasi Terhadap Nyeri Dismenore Pada Mahasiswi Universitas Muhammadiyah Semarang, skripsi, Universitas Muhammadiyah, Semarang

Faizah, J. (2000). Pemberdayaan wanita dalam bidang kesehatan. Yogyakarta: Yayasan Essentia Medica.

Gosana, H.F. (2001). Terapi Latihan Fisik Untuk Berbagai Penyakit. Jakarta: Pustaka Sinar Harapan

Hughes, Megan L. 2006. Critical Incident Stress Debriefing as a Trauma Intervention in First Nation Communities ( Jurnal Penelitian )

Keikos. (2007). Menstruasi. Diakses tanggal $27 \quad$ April 2012 dari http://keikos.biz/2007/06/17/menstru asi/

Kozier B., Erb G., Berman A., \& Snyder S.J, (2004), Fundamentals of Nursing Concepts, Process and Practice 7th Ed., New Jersey: Pearson Education Line

Melzack R, Wall PD. Pain mechanisms: a new theory. Science 1965;150:971-9
Morgan, G \& Hamilton, C. (2009). Obstetri \& ginekologi panduan praktis (edisi 2). Jakarta: EGC.

Priharjo, R. (2003). Perawatan nyeri. Jakarta. EGC.

Poter, P. A., \& Perry, A. G. (2005). Fundamental keperawatan konsep, proses dan praktek (Alih bahasa: $R$. Komalasari) (edisi 4). Jakarta: EGC.

Poter, P. A., \& Perry, A. G. (2006). Fundamental keperawatan (edisi 4). Jakarta: EGC.

Price, A. S., Wilson M. L., 2006. Patofisiologi Konsep Klinis ProsesProses Penyakit. Alih Bahasa: dr. Brahm U. Penerbit. Jakarta: EGC

Smith, R.P. (2003). Dysmenorrhea: Etiology, Diagnosis, and Therapy. Diakses tanggal 21 September 2011 dari http://www.omenshealthapta.org/csm20 03/4654.pdf

Simanjuntak, P. (2008). Gangguan haid dan siklusnya. In: Winkjosastro H., Saifuddin A.B., Rachimhadhi T. Ilmu kandungan. Jakarta : PT Bina Pustaka Sarwono Prawirohardjo, pp: 229-32.

Smeltzer \& Bare. (2002). Keperawatan medikal bedah. Edisi 8 Vol.1. Alih Bahasa: Agung waluyo. Jakarta. EGC.

Thangchai, K., Titavan, V., \& Boriboonhirunsarn, D. (2004). Dysmenorrhea in Thai adolecents: Prevalence, impact and knowledge of treatment. Journal of The Medical Association of Thailand, 3(87), 69-73. 